
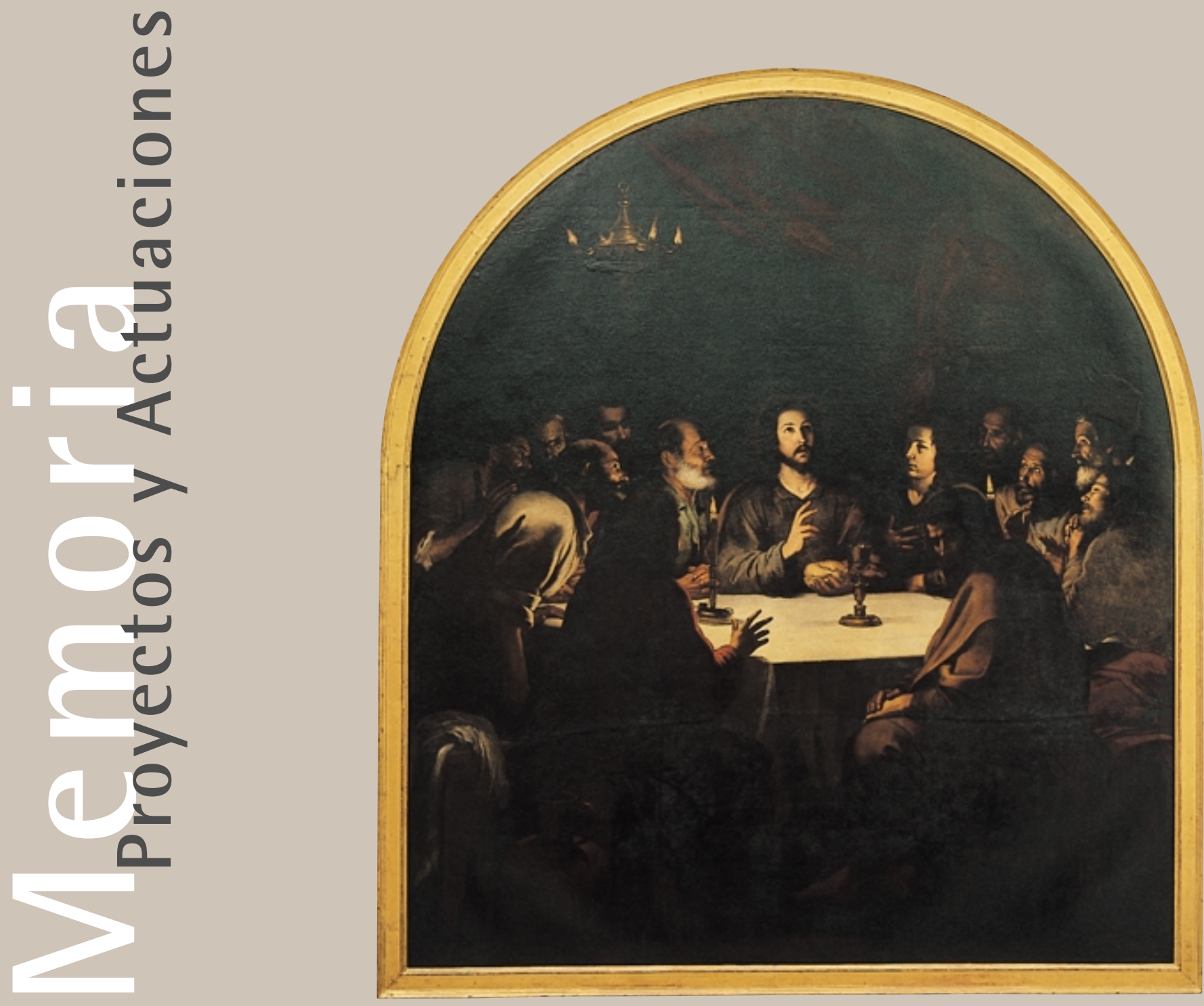

\title{
Intervención de la pintura "La Cena" de Bartolomé Esteban Murillo
}

\author{
Lourdes Núñez Casares \\ Francisco Gutiérrez Montero \\ Lourdes Martín García \\ Eugenio Fernández Ruiz
}

Centro de Intervención del IAPH 
$\frac{\pi}{0}$
$\frac{\Sigma}{\Sigma}$
$\Sigma$

2 Detalle de San Pedro antes de la restauración. Se pueden apreciar las pinceladas y los empastes que utiliza Murillo.

\section{Nacimiento de un estilo propio}

Murillo nació en Sevilla en 1617, siendo el menor de I 4 hijos; sus padres Gaspar Esteban y María Pérez lo bautizaron en la Iglesia de la Magdalena, de Sevilla, al igual que sus hermanos. Su situación económica era holgada ya que su padre era barbero cirujano, incluso tenía esclavos. Se quedó huérfano muy joven (1628) y se fue a vivir con su hermana Ana de Murillo, de la cual tomó el apellido Poco después de su nacimiento, el carácter político y económico por el que atravesaba el país (guerras de Italia, Flandes y Portugal) influyó en Sevilla, de tal manera que se agrava su situación al pasar de ser una ciudad con mucha vitalidad mercantil a la decadencia por el traslado de la actividad portuaria a Cádiz (1620).

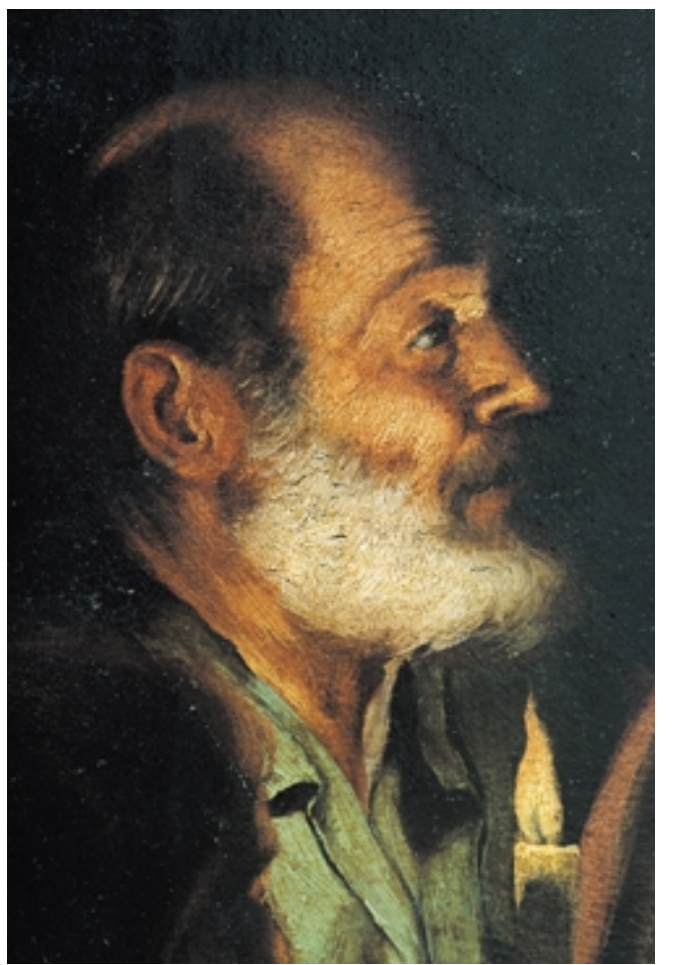

Algunos núcleos de la población eludieron la situación. La nobleza terrateniente, la burguesía con su actividad comercial y el clero, fueron los clientes y patronos de Murillo, llegando ser el pintor mejor pagado de la ciudad, siendo sus obras continuamente solicitadas y llevando una vida desahogada. A pesar de esto no se le exigió un arte elitista y sus clientes aceptaron la presencia de imágenes religiosas y profanas unidas en un sentimiento popular, espiritual y físico, siendo los personajes religiosos los que emanaban ternura y afectividad, suscitando en el espectador acercamiento, comprensión y amparo, necesidad imperiosa del pueblo, que atravesaba calamidades y que acudía a la fe espiritual como consuelo. La exposición de las obras en retablos y altares de iglesias, en las mansiones de la nobleza y burguesía tanto a nivel público como privado, provocó que sus obras fueran aceptadas a todos los niveles.
El proceso de aprendizaje de Murillo con Juan del Castillo comenzó, gracias a sus vínculos familiares, integrándose en el gremio de artistas y pintores, donde aprendió los elementos básicos de la pintura y, ya en sus primeras obras, se refleja la enseñanza adquirida. Diez años estuvo con este pintor, hasta que se trasladó Juan del Castillo a Cádiz. Aunque éste era uno de los cuatro pintores más destacados de Sevilla junto con Francisco de Herrera el Viejo, Pacheco y Juan de Roelas, se trataba de un pintor modesto y Murillo no sacaría gran provecho permaneciendo a su lado.

Aun así, la gran capacidad receptiva de Murillo hizo posible que tomara como referencia a estos pintores sevillanos, que aportaron grandes novedades estéticas a la pintura de su tiempo. Así, de Roelas tomó el color cálido y opulento, y la introducción de personajes pictóricos llenos de expresividad; de Herrera el Viejo, la pintura naturalista, vacía y de potente expresividad; y de Francisco de Zurbarán, el dibujo, su manera de modelar los volúmenes y plegar las telas.

La utilización de grabados y láminas para la composición y distribución de los personajes era un recurso muy utilizado por los pintores de la época y no por ello eran menos considerados. Es asombroso cómo con los medios de transporte tan lentos y precarios la divulgación del arte era tan extensa. La influencia de la pintura europea se muestra por su inspiración en estas estampas y grabados que reproducen obras de la escuela flamenca. Según Palomino, en 1658 Murillo viajó a Madrid, pudiendo estudiar este tipo de obras. Según otros autores, tras casarse con la noble Beatriz Cabrera y Sotomayor en 1645, regresó de Londres su ex-compañero Pedro de Moya, discípulo del pintor en el taller de Juan del Castillo, que le mostró copias de pinturas de Van Dyck y Rubens.

La influencia italiana en el tenebrismo se inspira en Caravaggio, en su manejo de la luz y los efectos claroscuros, y de José Ribera, pintor español residente en Nápoles.

En 1646, y tras la influencia de los distintos pintores, vemos cómo la renovación artística de Murillo surge en los lienzos del Convento de San Francisco, en Sevilla, contrato que llega por la necesidad de realizar once obras y al no encontrar "maestro consagrado" se le encarga a Murillo. El éxito fue rotundo.

La virtud fundamental de Murillo dentro de su estilo como pintor es haber sabido utilizar las fuentes de inspiración, adquiriendo en él una absoluta personalidad y con una capacidad inventiva que le lleva a concebir composiciones totalmente nuevas. El sentido del movimiento y del dinamismo propio del barroco frente al inmovilismo y la inexpresividad que mostraba la generación anterior pudo conseguirlo gracias a sus dotes de gran dibujante, captando todo tipo de gestos y actitudes de manera natural y espontánea, siendo un gran observador de la realidad. Fue el intérprete de su ciudad, su poder de plasmar el espíritu y el sentimiento hicieron posible que su mensaje fuese 
captado por el pueblo, y así verse reflejados en sus fisonomías y apariencias cotidianas.

El tratamiento de la luz a lo largo de toda su obra oscila de una iluminación general y uniforme a efectos contrastados de luz y sombra, especialmente adecuados para resolver escenas que se desarrollan en ambientes interiores. Estudia tonos de luz armoniosos para evitar bruscos contrastes entre la claridad y la oscuridad, dando la sensación de profundidad espacial.

Su sentido del color evoluciona de la época denominada "fría" a la "vaporosa" en la madurez, aplicando el pincel de manera cada vez más ligera e intuitiva.

\section{La obra: La Cena}

En 1649 una terrible peste asoló la ciudad de Sevilla, dejándola sumida en la pobreza, el hambre y la enfermedad, circunstancias que afectaron la vida de Murillo y que fueron captadas de forma admirable y realista en sus pinturas.

Esta obra, pintada para la Hermandad Sacramental de la parroquia de Santa María la Blanca, fue colocada en su altar el 30 de noviembre de 1650 I. Según señala Angulo Íñiguez, fue pintada para una capilla lateral del testero estrecho, si bien "el lienzo no podía tener las proporciones apaisadas tradicionales en el tema, so pena de representar la escena en escala mucho más reducida. Murillo, al recibir el encargo, hubo de estudiar cómo adaptar aquella historia, al nicho rehundido en el testero de la capilla."2

La ubicación de la obra no ha sido siempre este lugar; según la documentación transcrita por Montoto en el año 1745, el Hermano Mayor hace referencia a un cambio de ubicación sin especificar su nuevo emplazamiento. Ya por esta fecha no se encontraba en la Capilla Sacramental ${ }^{3}$.

En el año 1810 es depositada en el Alcázar, al ser requisada por el mariscal Soult, siendo devuelta de nuevo a la parroquia de Santa María la Blanca en 1813.

Este cuadro ha sido objeto de algunas restauraciones a lo largo de su historia. En 1738 la Hermandad Sacramental tenía intención de venderla para lo cual fue tasada por el pintor Andrés Rovira, quien no advirtió más defecto en el lienzo, que el estar "ahumado" y tener algunos remiendos en partes no perjudiciales. Posteriormente, en 1745, es de nuevo tasada por los pintores Domingo Martínez y Bernardo Lorente Germán, reafirmándose ambos en lo dicho por Andrés Rovira.

Murillo se basa en la estampa realizada por Boëce a Bolswert sobre la composición de Rubens, utilizando el tipo físico y los gestos de los comensales, la actitud de Jesús bendiciendo el pan, el tenebrismo creado por las vela que Murillo cambia por una lámpara, el fondo arquitectónico lo simplifica dejando sólo una columna y la cortina que la rodea, e invierte los personajes situados en primer plano. El tema de la obra

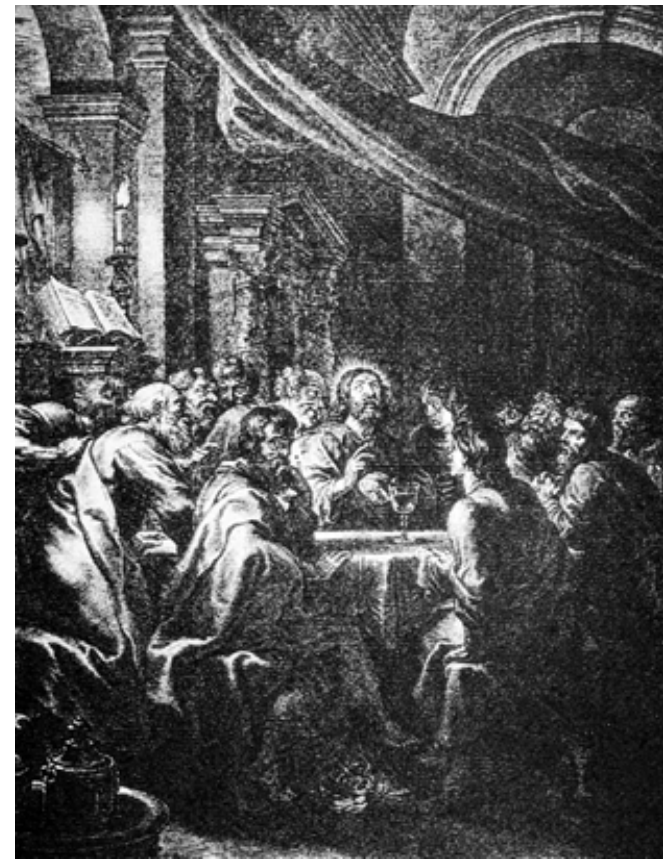

$\frac{⿱ 亠}{\square}$

es la Cena, tratada anteriormente por otros autores y, la encontramos en Alonso Vázquez, que se basó en dos estampas: la de Cort y la de Livio Agresti da Forlivetano, Pedro de Morales también toma como modelo la estampa de Cormelis Cort. ${ }^{4}$

Se pueden establecer dos cortes lineales frente a una línea horizontal formada por los Apóstoles. En la parte central, la mesa rompe esta horizontalidad al igual que la cortina y que la línea del eje de la composición formado por Jesús, el centro del cáliz y Judas. Todos estos elementos hacen que la composición sea sesgada.

Se pueden establecer tres momentos en la obra atendiendo a un análisis psicológico; la parte izquierda refleja el pasado todavía latente, representado por el cántaro y la madurez de la figura iluminada de San Pedro; la parte derecha el futuro inminente, simbolizándose en la figura de Judas Iscariote y la juventud de San Juan, y por último, la zona central, un poco elevada, que implica el momento presente de la bendición del pan.

La obra representa un episodio del Nuevo Testamento recogido por los Evangelistas 5. San Juan y San Mateo no describen la habitación, pero sí el momento de la cena, que es el reflejado en la obra, mientras que Marcos y Lucas la describen como una sala grande y amueblada.

El cántaro es un símbolo que tiene dos significados y que nos introduce en un contexto. El primero es la confianza en la palabra de Jesús, pues los Apóstoles tienen que seguir a un hombre que lleva un cántaro en los hombros para encontrar la ubicación de dicha sala; el segundo significado hace referencia a la misión del cántaro, de contener el agua con la que Jesús lava los pies a sus discípulos, junto con el lienzo con el que los seca, que está apoyado en un banco, dando así muestras de humildad y servicio a los demás. Este
3 Grabado copia de Rubens realizada por Boëce a Bolswert. 
$\frac{1}{0}$
$\frac{0}{\Sigma}$
$\Sigma$

4 Personaje de Judas Iscariote una vez terminado el proceso de restauración.

aparece representado en la zona inferior izquierda de la obra y Murillo lo resalta perfilándolo, mientras que el resto de la zona inferior aparece abocetado.

La ambientación arquitectónica y de mobiliario corresponden a la época en que transcurrió la vida del pintor. Esto lo podemos ver en las terminaciones de los bancos en los que están sentados los apóstoles, terminados en garras de león y en la lámpara.

Elimina todo tipo de adornos tanto en la mesa como en el entorno para no distraer la atención del espectador, y se centra en el momento que intenta plasmar la bendición del pan.

La representación de Judas Iscariote mirando hacia otro lado refleja lo que los evangelistas narran como el momento en que pensaba entregar a Jesús y había hablado ya con los jefes de los sacerdotes.

Nos encontramos ante la obra más tenebrista realizada por Murillo. Este se encuentra por medio de la representación del conjunto en un fondo oscuro para resaltar más la luminosidad de las figuras y la postura de los apóstoles, sencilla y acogedora, escuchando la palabra de Jesús, llenando la escena de una gran intimidad y buscando una relación humana entre ellos.

Es una obra especial porque Murillo trataba siempre de reflejar la sencillez de espíritu evangélico, aunque la pasión y muerte de Jesucristo son escasamente representadas. Según estudios sobre el significado de los colores, podríamos establecer que el uso del amarillo dorado que encontramos en las luces de las velas y la lámpara indica una especial importancia a lo espiritual y a lo intuitivo, algo de gran valor; el negro, que podemos ver en el fondo, sombras, etc., suele considerarse negativo, una amenaza o un temor; en cuanto al rojo púrpura, encontrado en la cortina, simboliza una responsabilidad agobiante, y también indica espiritualidad, poder supremo. Este mismo color se manifiesta en otras obras con la presencia de Jesús una vez azotado y vestido con un manto púrpura.

Aparece un estudio de los cuatro elementos: el agua que está oculta dentro del cántaro, la tierra que es el material con el que está realizado, y sobresalta los elementos espirituales como son el fuego y el aire, representado por la luz de las velas y el ambiente, o mejor dicho, la atmósfera que rodea la escena respectivamente.

El símbolo de la Santísima Trinidad viene reflejado por los tres puntos de luz, las dos velas y la lámpara dejando en un triángulo escaleno en cuyo centro se encuentra la figura de Jesús en la que se recoge la luz para sobresaltarlo.

La ausencia de adornos en la escena demuestra la sencillez con la que Murillo quiere conquistar al pueblo de Sevilla que en ese momento estaba atravesando por una época difícil.

La obra, una vez expuesta en la Capilla Sacramental en el siglo XVII, tuvo que se impactante para el espectador, ya que la iluminación por velas, jugando con un espacio reducido y el carácter tenebrista, hacía que los claros resaltaran aún más.

La realización de la Santa Cena dio pie a que, cuando se reforma la iglesia de Sta María la Blanca, perdiendo ésta el aspecto de sinagoga medieval, le encarguen cuatro obras más. De las cinco obras que poseía esta iglesia de Murillo, sólo queda la Cena. Dos de las otras se encuentran en el Museo del Prado, una en el Museo del Louvre y otra en una colección particular inglesa.

\section{PRIMEROS CONTACTOS CON LA OBRA: ANÁLISIS GENERAL}

Antes de entrar de lleno en los problemas más graves que tiene la obra, no podemos menos que hacer una descripción general de ella para poder comprender la magnitud de estos.

Nos encontramos ante un lienzo al óleo de formato vertical, acabado en su parte superior en medio punto. Es una obra tenebrista, por lo que hay un gran estudio de la luz-sombra, siendo más minucioso y detallista en la terminación del tema central, mientras que el resto es abocetado.

La obra va acompañada de un marco sencillo de media caña y dorado, estando éste realizado a base de una preparación blanca, bol y pan de oro. La batiente interna del marco presenta ocho tablillas de forma irregular, añadidas a éste mediante puntillas y colocadas arbitrariamente, que sirven para el ajuste del formato del bastidor al marco. 
El lienzo se encuentra reentelado, pero a través de la película pictórica se puede apreciar que está compuesto por dos piezas de tela cosidas en sentido horizontal, dos injertos en la zona superior de la obra y las costuras ladeadas de la tela de reentelado en sentido vertical.

Las pinceladas varían desde finas y largas arrastrando el pincel en las zonas oscuras, hasta pequeñas y cortas, con mucho movimiento y empaste en los rostros y en la mesa. El tratamiento de ejecución de los ropajes es comparable a los cuadros de Juan del Castillo y vemos en ellos la influencia que éste ejerce en Murillo, sin embargo podemos apreciar en la blusa verde del Apóstol que está a la izquierda de Jesucristo, cómo las pinceladas son más espontáneas y rápidas, apartándose de la terminación plana de Juan del Castillo, y que daría rienda suelta en el tratamiento de los ropajes en cuadros posteriores. En las manos, rostros y pan podemos apreciar la influencia de Zurbarán en las pinceladas cortas de los brillos con carga en el pincel, dando expresividad a los rostros.

La zona en penumbra de la obra llama la atención por la limpieza y transparencia con la que están realizados los oscuros, haciéndolos más intensos. Este estudio de la luz y la sombra con la creación de efectos de claroscuro es una evidencia notoria de que en el principio de la carrera de Murillo éste prestó atención a las directrices artísticas que derivaban de la pintura barroca italiana, esto es, el realismo, la espontaneidad popular y el manejo de la luz de la pintura de Caravaggio.

\section{PROBLEMÁTICA DE LA OBRA}

En un primer examen visual minucioso se detectaron cuatro problemas graves y que repercutirían en el tratamiento a realizar.

I. El primero de ellos era el bastidor, con ausencia de sistema de expansión en la zona superior (arco o medio punto) y con un grosor, tanto de los travesaños como de los largueros insuficientes, además de grietas, roturas y faltas de cuñas que producían una inestabilidad grave en el soporte.

2. El segundo problema consistía en una serie de hundimientos en la superficie pictórica, donde se ignoraban las causas que podían provocarlos, y las posibilidades fueron varias: falta de soporte y falta de preparación, ya que por el reverso, la tela de refuerzo no dejaba apreciar la causa del problema ni su magnitud.

3. Se detectó como tercer problema la separación existente entre la zona inferior del soporte original y la tela de refuerzo. La falta de adhesión en dichas zonas de ambas telas era patente.

4. El cuarto y último problema lo encontramos en desprendimientos tanto de la película pictórica como de la preparación en la zona superior.

\section{DESARROLLO Y SOLUCIONES}

\section{Bastidor}

La solución al primer problema fue el diseño de un nuevo bastidor. El antiguo estaba formado por un sistema de expansión en la parte inferior (zona rectangular) y ninguno en la parte superior (zona de medio punto). Desde la base al centro del medio punto medía $307 \mathrm{~cm}$ de altura y $274.5 \mathrm{~cm}$ de ancho. Ambas partes se encontraban divididas por un travesaño horizontal desde el cual partían otros dos travesaños para la zona superior, en disposición radial, y otros dos para la inferior en disposición vertical. El tipo de ensamble encontrado, tanto en la zona inferior como en la unión de ésta con el arco de medio punto, era machihembrado. En la zona superior, el sistema de ensamblaje era a media madera, lo que impedía el sistema de expansión en el arco de medio punto.

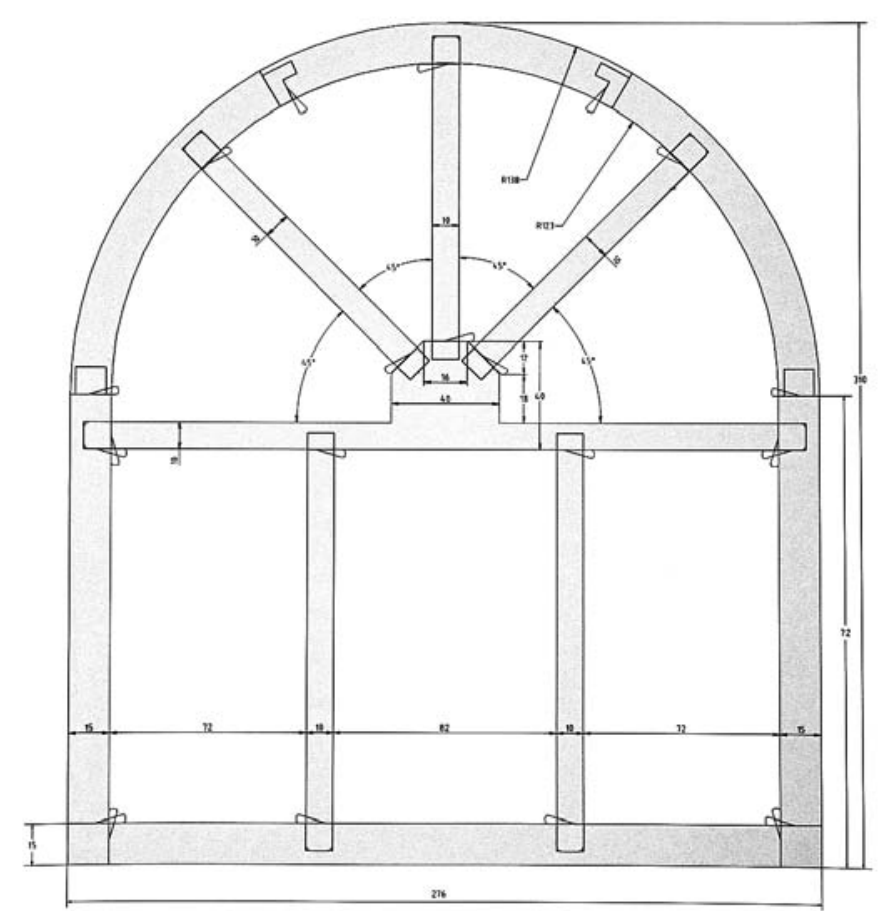

En el nuevo bastidor, la parte superior del medio 5 Gráfico del nuevo bastidor. Medidas expresadas en $\mathrm{cm}$. punto era la que creaba mayor dificultad. Fue necesario consultar con otros centros, como el museo de Bellas Artes de Sevilla, sobre los modelos de sistemas de expansión de bastidores de medio punto u ovalados, tanto en los siglos anteriores como en el actual, y se observó que estos sistemas eran insuficientes o nulos y muchos de ellos corrían el peligro de expandirse en forma lobulada, lo que perjudicaba la tela original en la abertura de los ensambles.

Por todo ello, mediante un análisis de compensación de fuerzas, que se realizó repartiendo éstas en cuatros sectores de iguales dimensiones, se conformaron así los cuatro largueros en forma de arcos, ensamblándolos entre sí mediante machihembrado, respetando la curvatura del larguero y sustentados 
por tres travesaños radiales dispuestos a $45^{\circ}$, partiendo estos últimos del centro geométrico del semicírculo superior. Este centro está ubicado en el travesaño horizontal superior, diseñado con la disposición de una pieza de medio octógono, suficientemente sólida para soportar las tensiones de los travesaños radiales.

La parte inferior (rectangular) estaba formada por dos largueros verticales, uno horizontal y un travesaño central en sentido horizontal, desde el cual partían dos travesaños dispuestos verticalmente que dividían el espacio en tres (Ver diseño del bastidor).

El sistema de ensamblaje entre largueros, y de estos al medio punto es machihembrado, entre larguero y travesaño en forma de horquilla. El corte de todos ellos es longitudinal y la sección rectangular. El tipo de madera utilizada es pino. Se protegió el bastidor con $\mathrm{Pa}$ raloid $\mathrm{B} 72$

\section{Hundimientos}

El segundo problema importante por resolver era el de los hundimientos que se apreciaban por la superficie pictórica. Se decidió realizar un estudio tanto analítico completo de los pigmentos y preparación como fotográfico (UV, IR, RX).

\section{A. Estudio Analítico:}

Se tomaron un total de diez muestras tanto de las zonas hundidas como en las que no y de las fibras de las distintas telas (original, reentelado y el tapacosturas).

Los resultados de los análisis nos informaron que los tres tejidos analizados, original, reentelado y tapacosturas, eran de lino. No se observa ninguna diferencia apreciable, en cuanto a composición química se refiere, entre las zonas que presentan hundimiento y aquellas en las que no hay.

6 Radiografía general de la obra.

\section{B. Análisis Radiográfico:}

Se realizó la radiografía completa de la obra con la que se obtuvo gran información que se puede resumir en los siguientes apartados:

- La estructura del antiguo bastidor del que ya hemos hablado anteriormente.

- Los clavos de sujeción de la obra al bastidor, pero dos de ellos en la zona superior del medio punto se mostraban sin lógica alguna.

- Dos arrepentimientos, uno de ellos en el rostro de Jesucristo, concretamente en la disposición de las cejas, y otro en la posición de la cabeza del apóstol de la derecha que está apoyado sobre la mesa.

- Las manchas oscuras, que en una lectura normal se asemejan a la falta de preparación y de película pictórica, distribuidas por toda la superficie y coincidiendo con las zonas de hundimientos superficiales, nos demostraban que algún motivo inexplicable las ocasionaba. Se descartaba la posibilidad de falta de preparación tras los análisis químicos efectuados anteriormente, pero a pesar de todo ello se realizó un estudio de las pinceladas, sobre todo las que llevaban más carga de color, y que coincidían tanto con las zonas hundidas como sin hundimientos, llegando a la conclusión de que éstas continuaban, con lo cual se descartaba del todo la posibilidad de que fuesen provocadas por falta de preparación o de película pictórica.

- El soporte está formado por dos telas unidas y cuyo cosido era oculto tras un tapacosturas de $1 \mathrm{~cm}$ de ancho dispuesto horizontalmente.

- Dos injertos, uno situado bajo la lámpara de forma rectangular y estrecha, y otro situado sobre la cabeza de un apóstol de la derecha, con forma más cuadrada y ambos situados en la zona superior de la obra.

- Dos roturas del soporte pictórico, una en sentido vertical que parte desde la cortina, pasa por el fondo y el rostro de San Juan llegando a tener dos bifurcaciones horizontales y terminando bajo éste en forma de triángulo. Otra en sentido horizontal, que va desde el borde periférico hasta el injerto situado bajo la lámpara.

- Faltas de preparación y película pictórica repartidas por la superficie pero más abundantes en la zona de la cortina, todas ellas de pequeñas dimensiones y de forma semejante al craquelado de la obra.

\section{Análisis Infrarrojos:}

El visionado con lámpara infrarroja proporcionó la información de ausencia de dibujo subyacente alguno.

\section{Examen mediante Luz Ultravioleta:}

Los repintes que se encontraban sobre la superficie pictórica sobrepasaban las lagunas de película pictórica y se encontraban repartidos por toda la superficie, pero la espesa capa de barniz actualmente oxidada de color verdusco no dejaba apreciar las dimensiones de los repintes más antiguos.

Viendo los distintos resultados analíticos, se hicieron catas de limpieza en zonas donde se apreciaban y no 

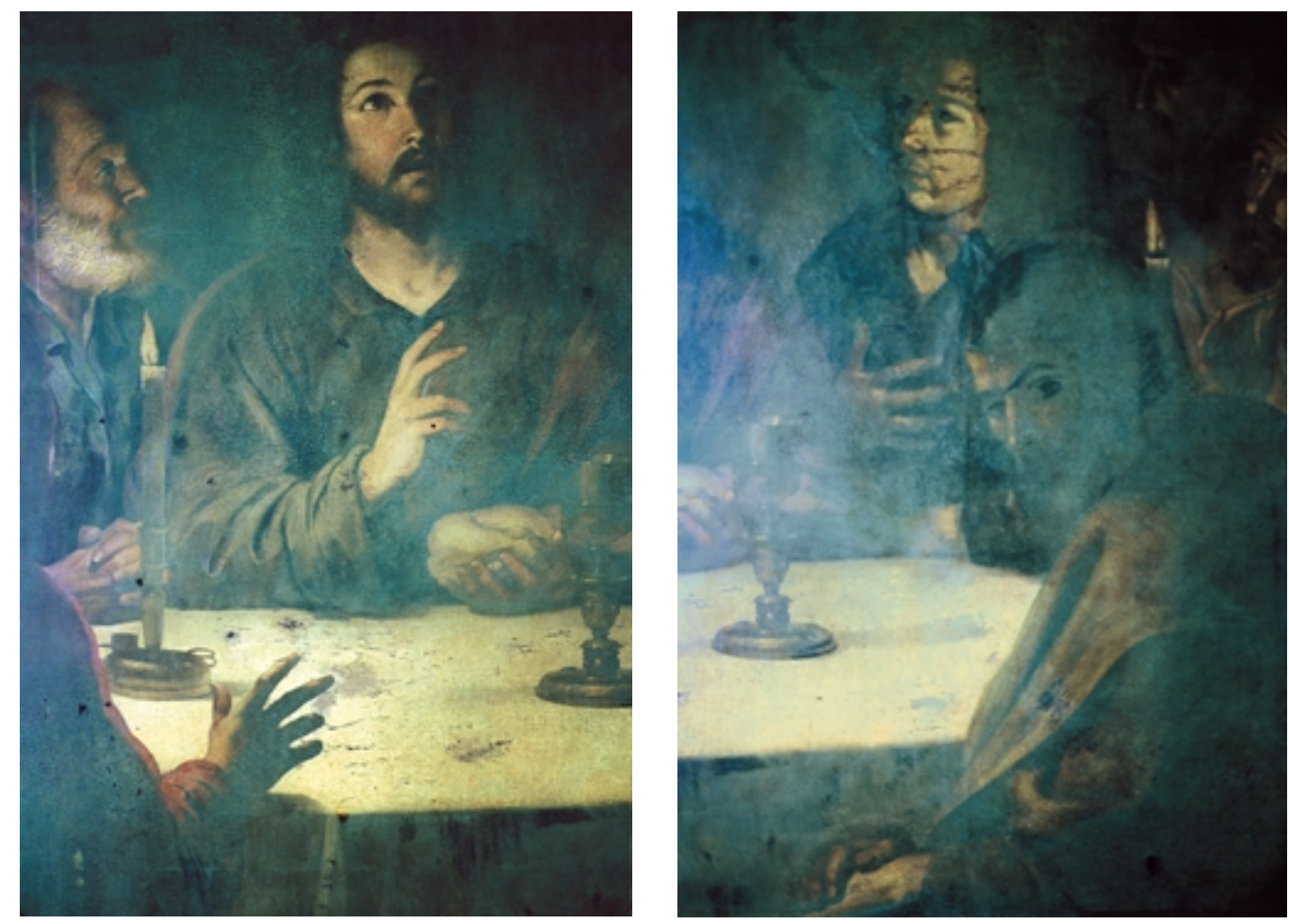

hundimientos de la superficie pictórica, para ello se realizaron los test de disolventes, comenzando con los de menos actividad a mayor, y con la ayuda de la lupa binocular, se decidió utilizar la mezcla de Isooctano e Isopropanol al 50\%. En dichas zonas se estudió la pincelada, al igual que anteriormente con la radiografía, y se descartó la idea de tratarse de estucos antiguos a bajo nivel y repintes. Se comenzó a pensar en la posibilidad de una capa intermedia entre la tela de reentelado y la original, cuyo grosor y composición hicieran posible su manifestación tanto radiográficamente como superficialmente.

\section{Falta de adhesión de la tela original con la de refuerzo}

La falta de adhesión de la tela original con la de refuerzo era el tercer problema, sobre todo en la zona inferior, donde el lienzo había sufrido bastante con los cambios de temperatura-humedad. Esto, acompañado de las deformaciones en superficie, obligaba a un nuevo reentelado de la obra.

El soporte original consta, pues, de dos telas cosidas en sentido horizontal. La costura es irregular y por ello no se pueden especificar las dimensiones exactas de las piezas. La inferior es de tamaño menor, teniendo $278 \mathrm{~cm}$ de ancho y variando en altura debido a la deformación que presenta desde $63^{\prime} 7 \mathrm{~cm}$ en el lateral izquierdo a $89 \mathrm{~cm}$ en el lado derecho.

La pieza superior de tela tiene $278 \mathrm{~cm}$ de ancho y la altura, midiendo desde el centro del medio punto hasta la costura, es de $238 \mathrm{~cm}$; el tapacosturas es de $1 \mathrm{~cm}$ de ancho y $278 \mathrm{~cm}$ de largo dispuesto horizontalmente.
La tela de refuerzo de lino consta de tres piezas cosila parte superior.

Antes de iniciar los procesos previos al reentelado de la obra se realizó una primera limpieza de la capa de para que penetrase mejor la coleta durante la fijación de la película pictórica, y se eliminaron los repintes que sobrepasaban el original con Tolueno y Dimetil Formamida $75-25 \%$.

Bajo estos repintes se encontraron cuatro tipos diferentes de estucos que hace pensar en cuatro restau-

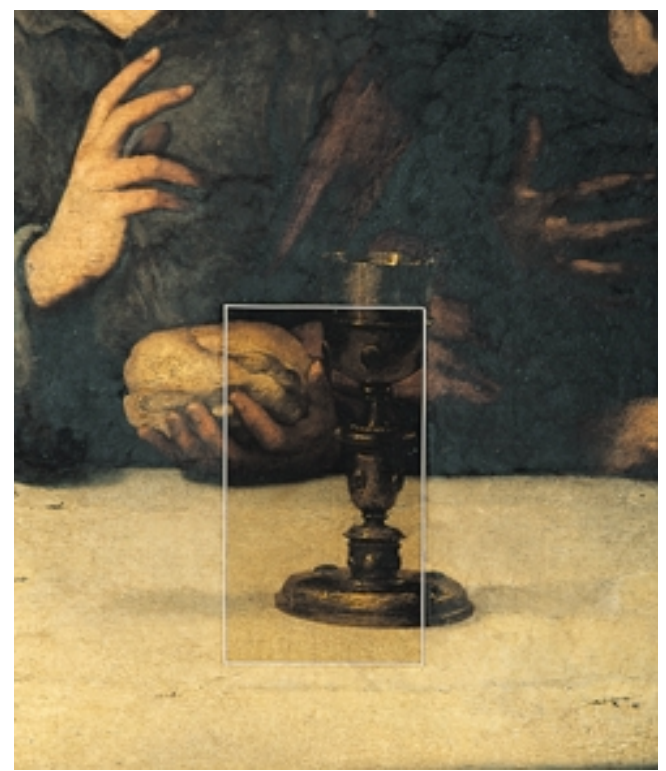
das en sentido vertical, con una ligera deformación en barniz oxidado con Isooctano e Isopropanol al 50\%
7 Detalle de la película pictórica con iluminación UV.

8 Detalle de la película pictórica con iluminación UV.
9 Fase de eliminación de barnices oxidados . Testigo de limpieza. 
$\frac{\pi}{\frac{1}{0}}$

10 Capa oscura encontrada en el reverso de la obra.

II Testigo de limpieza en la fase de eliminación de la capa oscura del reverso de la obra.

12 Reverso del soporte pictórico una vez limpio y con los parches de gasa de seda en roturas, costura de ambas telas y la zona perisférica de la obra.
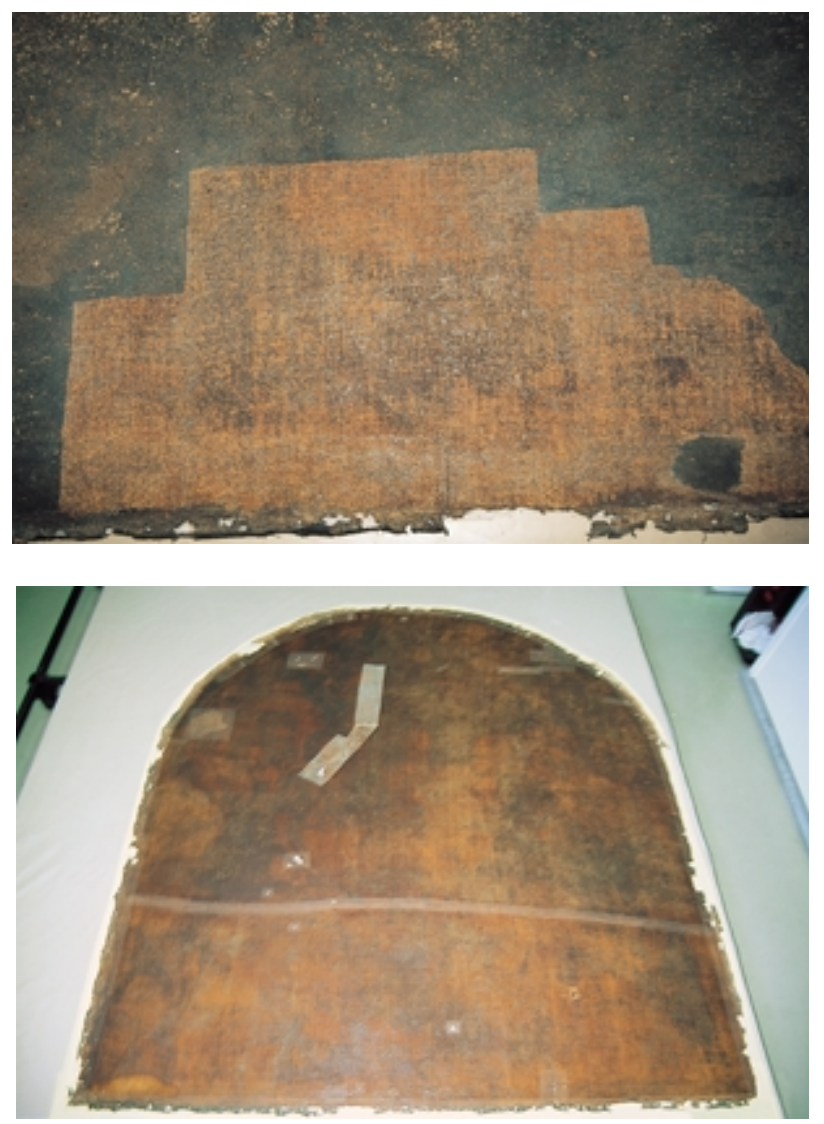
sado la obra:

a) Estuco blanco: muy duro, posiblemente por tener mucha cantidad de cola en su composición. Se encontró en zonas muy puntuales.

b) Estuco negro: blando, no rebasa el original, de fácil eliminación.

c) Estuco tierra oscura: blando, sobrepasa mucho el original y es de fácil eliminación, hay gran cantidad de ellos localizados en la zona perimetral de la obra y de gran espesor.

d) Estuco ocre: muy duro, sólo se encuentra en la zona superior cortina, bordes, y fondo.

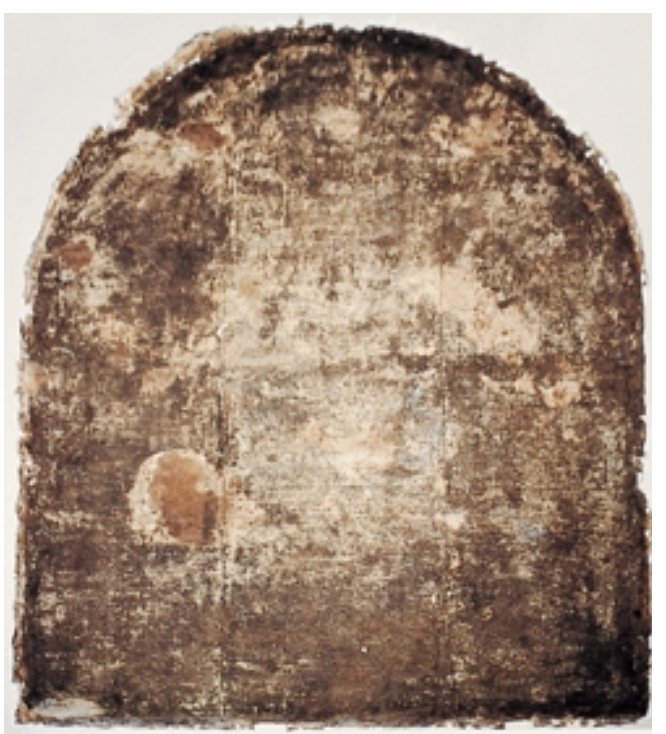

raciones, como mínimo, diferentes por los que ha pa-

La trama de la tela del reentelado antiguo se encontraba en perfecto estado debido al grosor del hilo mientras que la urdimbre se deshacía; esto dificultó su separación de la tela original a pesar de realizarse en diagonal para evitar un posible desgarro de las fibras.

Eliminada la tela de refuerzo, se observó cómo una capa oscura cubría gran parte de la superficie de la tela original, y que las lagunas de dicha capa correspondían tanto con los hundimientos visualizados por el anverso como con las zonas oscuras aparecidas en la radiografía. Tanto las deformaciones que dicha capa producía en todos los estratos de la obra, como la rigidez que aportaba a la tela original, ausentándola de flexibilidad y movimiento, marcaron la decisión de proceder a su eliminación. Las pruebas que se realizaron para ello fueron tanto con humedad como con disolventes (de poca intensidad para no dañar la tela original, la capa de preparación y la película pictórica) ayudados con el bisturí. Se determinó eliminarla a punta de bisturí y, en zonas muy puntuales, se utilizó la aplicación de humedad.

Se analizaron químicamente varias muestras informándonos los resultados que la capa del reverso de la tela original está compuesta de carbonato cálcico y tierras (cuarzo y silicatos) mezclado con cera (posiblemente parafínica), resina (posiblemente terpénica) y trazas de aceite (posiblemente secante).

El grosor de dicha capa en la zona periférica era de 0'8 mm al igual que la tela original, la capa de prepa- 
ración y la película pictórica juntas, variando el grosor y aumentando en la zona central ya que no era totalmente homogénea.

Tanto en la zona de los injertos, como en la zona de la grieta se encuentra con la ausencia de dicha capa, sin embargo, vemos cómo en estas zonas hay acumulación de gacha que contiene carbonato cálcico e hidróxido cálcico para crear volumen. La rigidez proporcionada por el grosor de la capa oscura del reverso nos hace pensar que fue la causa de dichas roturas al manejar el lienzo en cualquier maniobra.

La justificación de por qué aplicaron dicha capa al reverso del lienzo era el funcionamiento como aislante de la humedad de la pared, y su aplicación fue bastante anterior a la rotura del lienzo y a la de los injertos.

Debido al grosor y a la dureza de dicha capa de protección, el trabajo de su eliminación fue lento y delicado, ya que el soporte original se encontraba bastante débil y cualquier error podía producir un desgarro. Aparte de esto no hay que olvidar la vibración que se producía y, aunque la película pictórica estaba protegida, era un problema importante a tener en cuenta, por ello a medida que se iba eliminando la capa del reverso se comprobaba el anverso táctil y visualmente.

La duración de dicha operación comenzó el I de julio de 1998 y concluyó el 23 de enero de 1999, desde octubre a enero se incorporó un ayudante y se amplió el horario a mañana y tarde. Haciendo una recopilación de las horas empleadas para realizar dicho trabajo se llegó a un total de 2.229 horas, que expresadas en meses corresponden a 14 meses, 3 semanas y media para una sola persona en horario laboral de 40 horas semanales.

Se dividió la obra en tres zonas verticales, de las cuales se limpió una de ellas, y el peso de esa capa, una vez eliminada de la obra, fue de 2.360 gr., que da una idea del grosor, la rigidez y el peso que debía soportar la obra y el motivo de las grietas que en el soporte se habían producido.

Una vez realizada la limpieza del reverso se procedió al estudio de las fibras y las telas que compone el soporte:

El soporte original, como se ha comentado anteriormente, estaba compuesto de dos piezas, ambas de lino, unidas mediante un cosido a punto por cima. La torsión del hilo, tanto de las telas como del tapa-costura, es en "Z" y el número de cabos es múltiple. La construcción interna o tipo de ligamento es sarga compuesta (vulgarmente mantelillo), pero el número de pasadas y el dibujo que forman es completamente distinto, siendo la de la zona superior más sencilla y la inferior mucho más compleja. El número de hilos de trama y urdimbre por $\mathrm{cm}^{2}$ de ambas varía de $15 \times 15$ a $16 \times 15$ en algunas zonas. Este tipo de tela de mantelillo repercute en la textura de la superficie pictórica creando una vibración propia de los cuadros realizados en este tipo de telas propios del Siglo. XVII.
Tanto la tela del reentelado como la de los injertos es de lino, la torsión en "Z", en número de cabos múltiples y el tipo de ligadura es tafetán en todos los casos, sólo varía el grosor y el número de hilos por $\mathrm{cm}^{2}$.

\section{Preparación para el reentelado:}

Tras el estudio de la fibra se procedió a la aplicación de una mano de cola por el reverso y a la colocación de parches con gasa de seda natural por la zona perimetral de la obra, en la costura de ambas telas, en las roturas existentes, en los injertos y en los pequeños desgarros y rotos que se encontraban en la tela original, ya que se encontraba muy debilitada.

La tela de lino utilizada para el reentelado tuvo que ser cosida a otra, ya que las medidas industriales eran
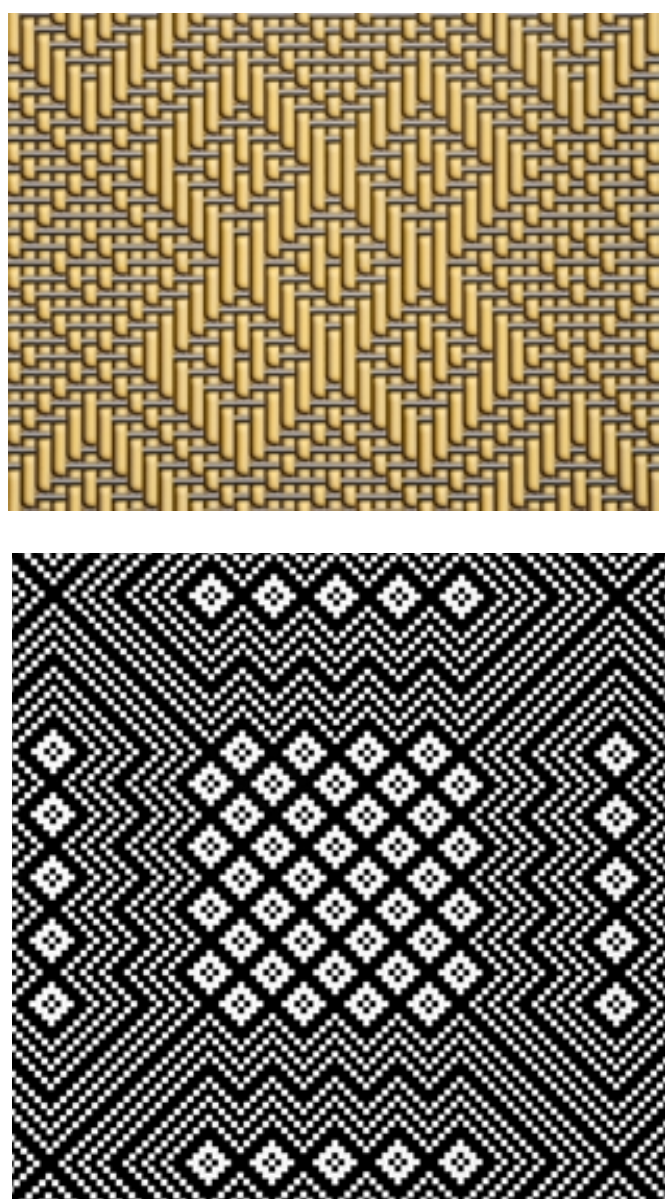

13 Gráfico del estudio de la construcción interna de la tela de la zona superior de la obra."Sarga compuesta".

14 Gráfico del estudio de la construcción interna de la tela de la zona inferior de la obra."Sarga compuesta"

I5 Gráfico del estudio de la construcción interna del tejido de los injertos y la gasa de seda de los parches. "Tafetán"

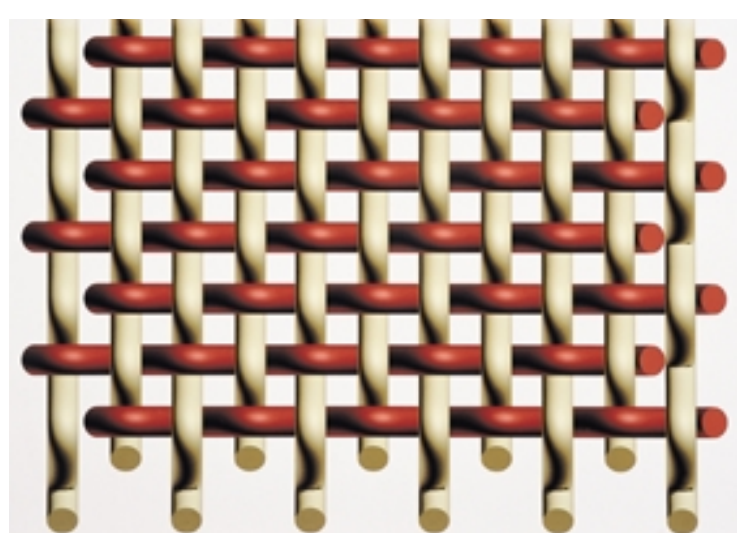


$\frac{1}{0}$
$\frac{0}{\Sigma}$
$\Sigma$

insuficientes para poder tensar en el telar este gran formato. Para ello se utilizó un "pespunte" a máquina. Tras ello se lavó y montó en el telar metálico, aplicándole una mano de agua cola a la zona marcada con las dimensiones y la forma original del lienzo.

\section{Reentelado:}

La prueba de encogimiento realizada en el lienzo original antes de ser desmontado del bastidor fue negativa, pudiendo utilizar adhesivos acuosos de igual manera tanto para la fijación como para el reentelado. El reentelado fue a la gacha con la receta y el método tradicional, al ser un cuadro de gran formato se necesitó un equipo de seis personas tanto para la aplicación de la gacha en ambas telas como para desplegar el lienzo desde el rulo a la zona previamente marcada de la tela nueva.

Este equipo se turnó de dos en dos personas para el planchado, sobre el puente, de la obra. El número de planchados fue cinco, siendo el último el realizado aplicando humedad superficialmente.

Tras la eliminación de los papeles de protección en el mismo telar se procedió al montaje en el bastidor utilizando grapas inoxidables.

\section{Desprendimientos de la preparación y la película pictórica}

El cuarto y último problema residía en la existencia de una gran cantidad de desprendimientos en la parte superior (zona de la cortina), y tras el estudio de los problemas anteriores y los motivos por los cuales aplicaron la capa de protección por el reverso hace pensar

16 Detalle de la fase de estucado de la zona superior "cortina".

17 Detalle final de la reintegración del manto de Judas Iscariote.

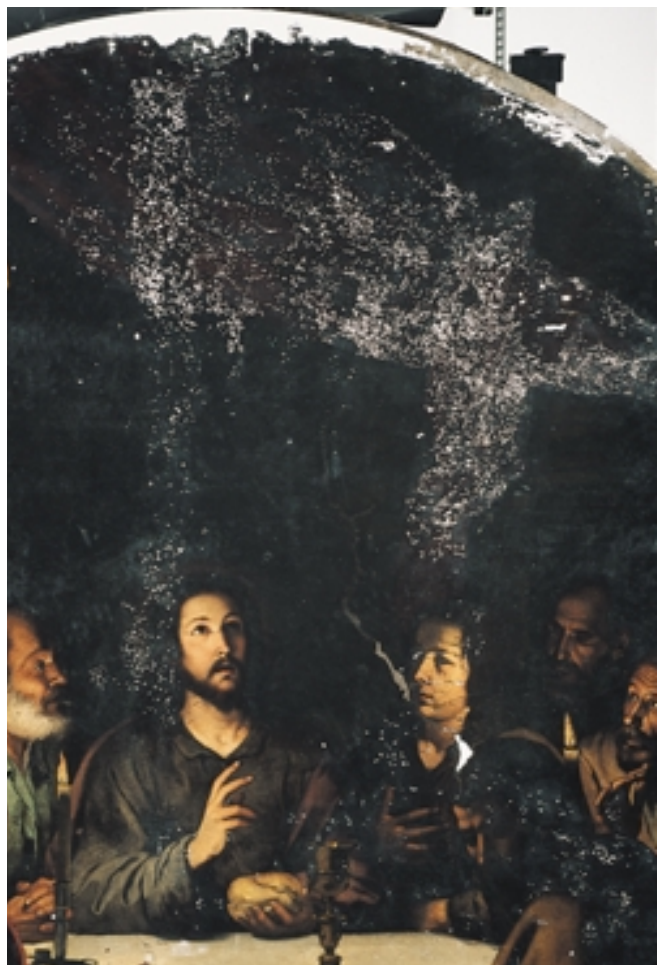

que en el lugar donde la obra estuvo ubicada existían focos de humedad, sobre todo en la parte superior de medio punto, lugar en el que se encuentra la cortina, que al estar realizada con mayor empaste con tierra roja sufre más los cambios de dilatación producidos por la temperatura- humedad, provocando la pérdida tanto de preparación como de película pictórica.

La fijación de la capa de preparación y de la película pictórica se realizó con coleta y papel de seda y se reforzó durante el reentelado. Las faltas o lagunas estaban reintegradas directamente sobre el soporte y para su eliminación se utilizaron los disolventes mencionados anteriormente en los repintes.

El tratamiento realizado en esta zona es igual al resto de la obra, pues una vez montado en el bastidor se procedió a realizar una segunda limpieza con los mismos disolventes utilizados en la primera. Posteriormente se dio un primer barnizado mediante brocha con barniz Surfin y se comenzó en las lagunas de soporte existentes a la colocación de injertos con gasa de algodón. Estos se encontraban en la zona perimetral de la obra.

Se estucaron las lagunas de preparación con sulfato de cal y cola de conejo. Las mayores, que se encontraban en los bordes de la obra, se realizaron con textura. Se reintegraron éstas con técnica acuosa y se procedió al barnizado mediante brocha.

La reintegración con pigmentos al barniz de las lagunas fue mediante líneas y puntos para crear vibración. El último barnizado se realizó pulverizado.

El día 4 de abril de 2000 se trasladó la Ultima Cena de Murillo a Santa María la Blanca de Sevilla.

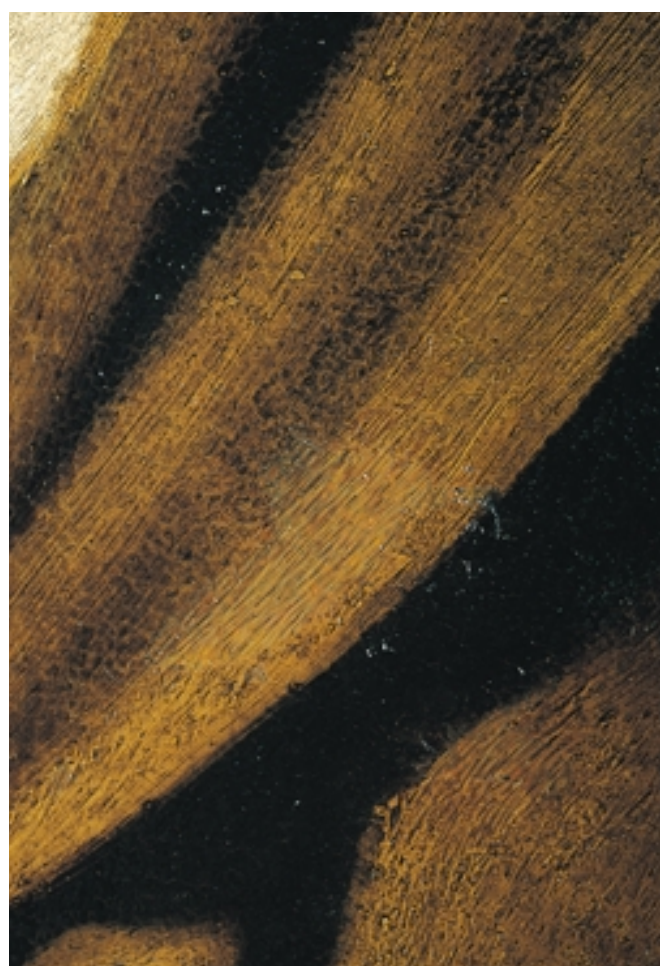




\section{INVESTIGACIÓN ANALÍTICA}

\section{Análisis estratigráfico}

Se tomaron un total de once muestras de pintura representativas de los diferentes colores presentes en el cuadro así como de algunas zonas del mismo en las que se observaba un ligero hundimiento de la superficie pictórica. Las muestras extraídas, de tamaño inferior al milímetro, se tomaron en lugares no estratégicos y aprovechando siempre las lagunas o grietas en la pintura.

La metodología de trabajo seguida fue la siguiente:

- Examen preliminar con el microscopio estereoscópico de los fragmentos de pintura extraídos y preparación de la sección transversal o estratigrafía.

- Observación al microscopio óptico con luz reflejada de la sección transversal.

- Estudio al microscopio electrónico de barrido y microanálisis elemental mediante energía dispersiva de rayos $X(E D A X)$ de la sección transversal.

La pintura presenta un capa de imprimación, de color marrón rojizo, constituida por tierras y calcita. Su espesor oscila entre 125 y $300 \mu$.

No se observa ninguna diferencia apreciable, en cuanto a composición química se refiere, entre las zonas que presentan hundimiento y aquellas en las que no hay.

Las estratigrafías son muy sencillas. Están constituidas básicamente por la imprimación, una capa de color y la capa protectora o barniz. Los distintos colores de la capa pictórica tienen la siguiente composición:

- Los tonos rojizos están compuestos por laca roja y tierra roja mezcladas con pequeñas cantidades de blanco de plomo y/o carbón animal, según el tono deseado.

- Los ocres resultan de la mezcla de blanco de plomo y ocre. El amarillo de la lampara está constituido por amarillo de plomo y estaño, ocre, tierra roja y sombra.

- Los blancos son de blanco de plomo.

- El color verde se ha obtenido de la mezcla de azurita con amarillo de plomo y estaño, un poco de ocre y blanco de plomo.

- Las carnaciones están compuestas por blanco de plomo y pequeñas cantidades de bermellón y tierra roja.

- Los tonos marrones están constituidos por sombra, blanco de plomo, calcita y carbón.

En el estudio se han identificado los siguientes pigmentos:

- Blancos: blanco de plomo (carbonato básico de plomo) y calcita (carbonato cálcico)

- Rojos: tierra roja (silicatos arcillosos coloreados por óxidos de hierro), bermellón (sulfuro de mercurio) y laca roja (colorante orgánico fijado sobre una carga inerte, generalmente hidróxido de aluminio)

- Amarillos: ocre (aluminosilicatos coloreados por óxidos de hierro hidratados) y amarillo de plomo y estaño (óxido de plomo y estaño)

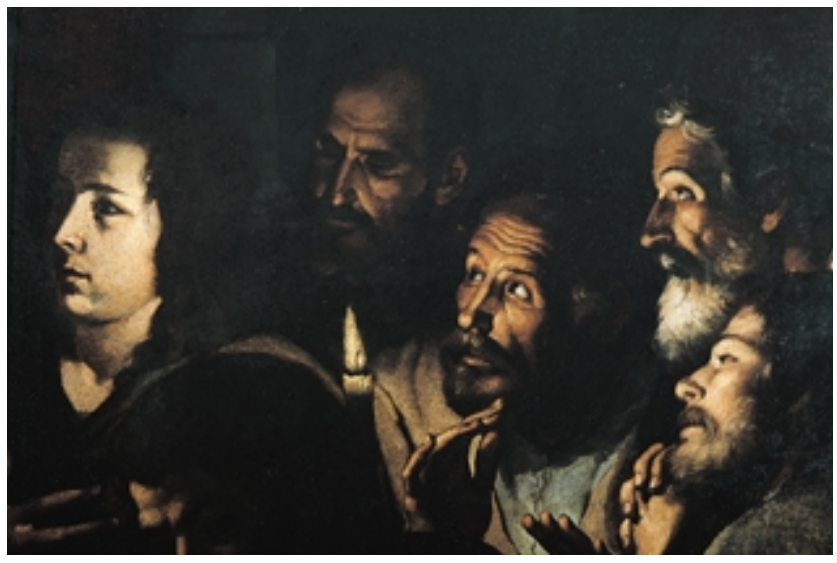

$\frac{\pi}{\square}$
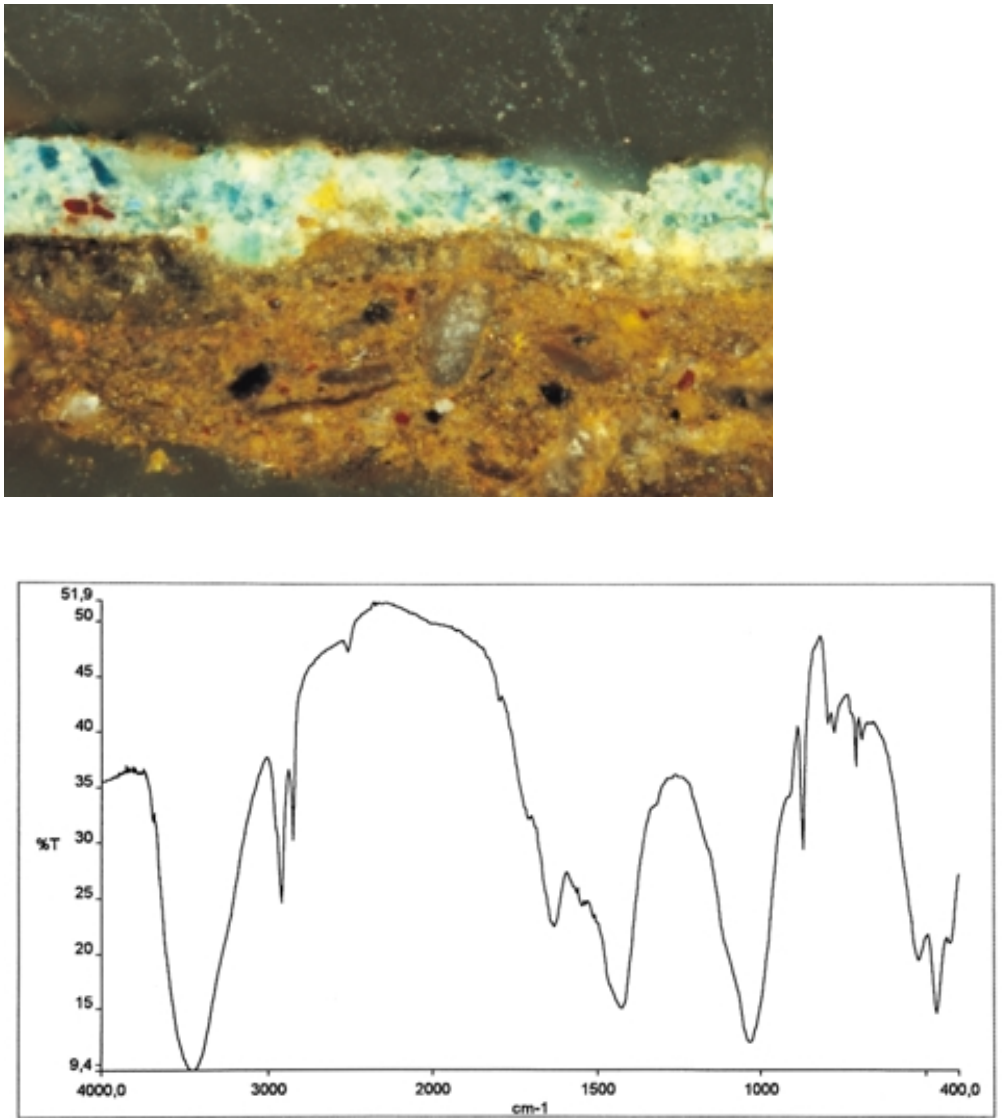

- Azules: azurita (carbonato básico de cobre)

- Marrones y pardos: tierras (silicatos arcillosos coloreados por óxidos de hierro) y sombra (silicatos arcillosos con óxidos de hierro y manganeso)

- Negros: carbón animal (carbón y fosfato cálcico)

\section{Soporte textil}

Se estudiaron las fibras textiles correspondientes a los diferentes tejidos encontrados en la pintura: tejido original, reentelado y tapacosturas. También se llevó a cabo la identificación de las fibras de un pequeño fragmento de papel encontrado entre la pintura y el estuco.
18 Detalle de los rostros de los apóstoles una vez concluido el proceso de restauración.

19 Sección transversal de una muestra de pintura de la camisa verdosa de San Pedro, 200X.

20 Espectro infrarrojo de la capa oscura encontrada en el reverso 
$\frac{\pi}{\infty}$
$\frac{1}{\Sigma}$
$\Sigma$

2I Detalle del rostro de San Juan en la fase de limpieza. (la ubicación de esta diapositiva y la siguiente no está determinada de antemano. Elegir lugar según necesidades de diseño. Tienen que ir juntas)

22 Detalle del rostro de San Juan una vez concluido el proceso de restauración.
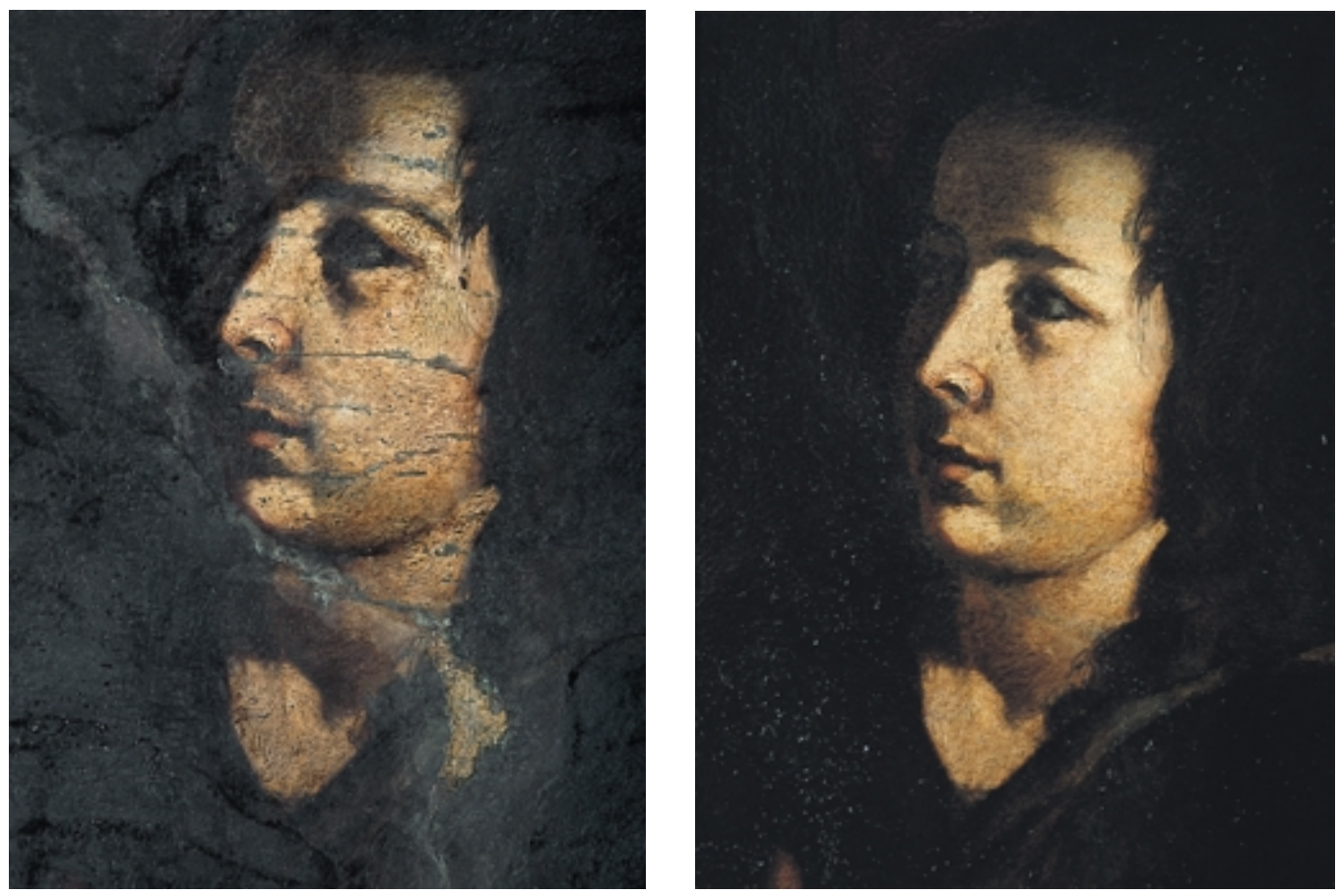

El estudio e identificación de las fibras se llevó a cabo mediante la observación de la apariencia longitudinal de las mismas (morfología, diámetro, agrupaciones, ...) al microscopio óptico con luz trasmitida polarizada. Los tres tejidos analizados, original, reentelado y tapacosturas, son de lino.

El papel encontrado entre el estuco y la pintura presenta fibras de lino (mayoritarias) y de algodón así como pequeños fragmentos de madera en los que se observan punteaduras areoladas características de la madera de conífera. La presencia de elementos característicos de la madera nos informa de que la fecha de fabricación de este papel es posterior al siglo XIX fecha en la que comienzan a utilizarse las fibras madereras en la industria papelera.

\section{Análisis espectroscópico}

Mediante espectrometría infrarroja por transformada de Fourier, empleando el método de dispersión y prensado de muestras en una matriz de bromuro potásico, y utilizando un rango espectral de 4000 a 400 $\mathrm{cm}^{-1}$, se han analizado muestras correspondientes a distintos materiales: barniz, adhesivo y capa oscura en el reverso del lienzo.

La muestra de barniz se extrajo utilizando como disolvente una mezcla de isooctano e isopropanol al $50 \%$, detectándose la presencia de una resina natural de naturaleza posiblemente terpénica.

En los adhesivos del reverso se detecta la presencia de gacha, adhesivo constituido fundamentalmente por almidón y cola proteica.
La capa oscura del reverso está constituida por tierras (carbonato cálcico, cuarzo, silicatos, óxido férrico), cera parafínica y trazas de aceite secante.

20 Espectro infrarrojo de la capa oscura encontrada en el reverso

\section{Análisis radiográfico}

Para la realización del análisis radiográfico se necesitaron como sistema detector y de registro de la imagen $32 \mathrm{~m}$ de película radiográfica continua empaquetada (rollpac) STRUCTURIX D7, cortadas en 10 tiras de $320 \mathrm{~cm}$ cada una, éstas fueron expuestas con una tensión de $100 \mathrm{kV}$, una corriente catódica de $40 \mathrm{~mA}$ y un tiempo de exposición de 75480 ms a una distancia foco-película de $865 \mathrm{~cm}$. La película tuvo un revelado automático de 8 minutos a 30 oC en revelador GI35.

\section{Reflectografía infrarroja}

En el análisis reflectográfico se utilizó una cámara Grunding con tubo Vidicom Infrarrojo sensible a una longitud de onda de $2000 \mathrm{~nm}$, realizando un barrido por toda la superficie del lienzo buscando cualquier tipo de dibujo subyacente, firma o inscripción que finalmente no se encontró. 
Notas:

I. Libro de Actas de 1755. Fols. 88 y 88 v $^{\circ}$. Montoto, S.: Murillo. Sevilla, 1923. Pág. 42.

2. Angulo Íñiguez, D. Murillo. Colección Arte Hispalense, vol. 27.

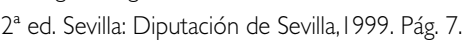

3. Montoto, S.: Op. Cit.

4. Navarrete Prieto, B. La pintura andaluza del siglo XVIII y sus fuentes grabadas. Madrid: Fundación de Apoyo a la Historia del Arte Hispano, 1998, Pág. 194

5. San Mateo 26,20-29, San Marcos 14,22-25, San Lucas 22,7-20 y San Juan 13.
Bibliografía:

ANGULO ÍÑIGUEZ, D. Murillo, vol. 27, Colección "Arte Hispalense" 2a edición, Sevilla, 1999. Diputación de Sevilla.

ANGULO ÍNIIGUEZ, D. Murillo. Su vida, su arte, su obra. Madrid. Espasa Calpe, 1981.

ARRIGOÑI, L. Y BERTELLI, C. La pinacoteca de Brera. Milano. F. Garola Editore. 1983.

CENTRE INTERNATIONAL D'ETUDE DES TEXTILES ANCIENS. CIETA. Lyon. Frances Techniques. 1979.

GREGG M. FURTH. El secreto mundo de los dibujos. Barcelona. Luciérnaga. 1992.

MONTOTO, S. Bartolomé Esteban Murillo. Sevilla. Estudio biográfico y crítico. 1923

NAVARRETE PRIETO, B. La pintura andaluza del siglo XVII y sus fuentes grabadas. Madrid. Ed. Fundación de Apoyo a la Historia del Arte Hispano. 1998

NUEVO TESTAMENTO. Madrid. San Pablo. 1996.

PÉREZ SÁNCHEZ, A. Murillo. Madrid. Ed. Electa España S.A. 2000.

VALDIVIESO, E. La obra de Murillo en Sevilla. Sevilla. Diputación Provincial, 1982.

VALDIVIESO, E. Murillo. Sombras de la tierra, luces del cielo. Madrid. Silex, 1990.

\section{Equipo de trabajo}

Proceso de restauración, informe técnico y documentación gráfica: M a Lourdes Núñez Casares. Restauradora. Taller de Pintura.

Departamento de Tratamiento.

Ayudante Restaurador eliminación capa reverso:

Guillermo Daza Puerto

Equipo de reentelado:

Dirección: Lourdes Núñez Casares

Rocío Vigueras Romero

Olga Fernández Agnus

Cinta Rubio Faure

Guillermo Daza Puerto

Eva Claver de Sardi
Análisis químico:

Francisco Gutiérrez Montero. Químico. Laboratorio de Química. Departamento de Análisis.

Lourdes Martín García. Química. Laboratorio de Química. Departamento de Análisis.

Fotografía, IR, UV y Radiografía:

Eugenio Fernández Ruiz. Fotógrafo-Radiólogo.

Laboratorio de Fotografía. Departamento de Análisis.

Dirección y Coordinación:

Pedro Castillo Pérez. Jefe del Departamento de Tratamiento. 